

\section{El migrante de tierra lejana}

El migrante de tierra lejana camina andante y perseverante bacía una tierra distante y añorada.

Tiene la esperanza de algún día llegar sano a la tierra prometida que cambiara su destino, un migrante lejano.

Cada migrante sufre la nostalgia de dejar a su familia, no importa cuántas lágrimas, penas y sufrimiento pase en su camino el migrante seguirá adelante con la frente en alto sin perder el horizonte de su destino.

El norte es su esperanza para cambiar su vida, Jesucristo ilumina su camino el migrante lejano llegará a su destino. Fernando

\section{Ulises Rivera}

Técnica: Acuarela 


\title{
5. Algunas consideraciones sobre la caravana migrante centroamericana en Piedras Negras, Coahuila ${ }^{1}$
}

Jesús Frausto Ortega ${ }^{2}$ Juan Parra Ávila ${ }^{3}$

DOI: https://doi.org/10.5377/pdac.v15i0.8117

Recibido: 28/05/2019 - Aceptado:24/06/2019

\begin{abstract}
Resumen: El objetivo de este artículo es realizar un análisis sobre algunas características asociadas a la caravana migrante centroamericana que llegó a Piedras Negras, Coahuila en febrero de 2019. Se aplicaron 535 cuestionarios y se agregaron 5 la prueba piloto para un total de 540. Además, se realizaron 6 entrevistas realizadas a población local; se hizo una revisión hemerográfica de la prensa local y regional y se consultó diversas fuentes secundarias e información estadística. Entre las conclusiones se tiene: las y los migrantes salen de sus países por falta de trabajo y de oportunidades económicas; aunado a lo anterior las condiciones de inseguridad y violencia en sus países son variables relevantes para tomar la decisión de migrar; su objetivo es llegar a Estados Unidos para pedir asilo político; en su tránsito por México algunos enfrentaron maltratos de autoridades mexicanas. La opinión que tiene la población local de la caravana es ambivalente: tanto de apoyo solidario, y de ayuda de la sociedad organizada, como de rechazo asociado con la idea de que las y los migrantes hacen uso de recursos que los nigropetenses no tienen.
\end{abstract}

Palabras clave: caravana migrante; centroamericanos; Piedras Negras; migración.

\section{Some considerations about the Central American migrant caravan in Piedras Negras, Coahuila.}

\begin{abstract}
The objective of this article is to do an analysis on some characteristics associated with the Central American migrant caravan that arrived in Piedras Negras, Coahuila in February 2019. 535 questionnaires were applied and 5 of the pilot test were added for a total of 540. In addition, 6 interviews were carried out with the local population; a hemerographic review of the local and regional press was made and various secondary sources and statistical information were consulted. Among the conclusions are: migrants leave their countries due to lack of jobs and economic opportunities; in addition to above, the conditions of insecurity and violence in their countries are relevant variables to make the decision to migrate; the goal is to reach the United States and ask for political asylum; in their transit through Mexico some faced abuse of Mexican authorities. The opinion of the local population of the caravan is ambivalent: both solidarity support and help from organized society, and rejection associated with the idea that migrants make use of resources that Nigropetenses do not have.
\end{abstract}

Keywords: migrant caravan; Central Americans; Piedras Negras; migration.

\section{Introducción}

Por muchos años México ha sido lugar de origen de la migración indocumentada de mexicanos que van hacia Estados Unidos en búsqueda de mejores condiciones de vida. De esa manera, la frontera norte mexicana tradicionalmente ha experimentado el cruce de esos connacionales. Sin embargo, el país también es un importante lugar de tránsito de migrantes centroamericanos que, de la misma manera, llegan a las ciudades fronterizas en su camino a ese país. Guatemala, Honduras y El Salvador -el denominado Triángulo Norte de Centroamérica (TNC) se han convertido en importantes expulsores de esa migración. Así, cada año transitan por México alrededor de
400 mil migrantes indocumentados, en su mayoría procedentes de esos países (Márquez, 2015, pág. 159). Esto ha provocado que las detenciones por las autoridades de migración mexicanas se incrementen. Al respecto López (2013, pág. 85) con base en estadísticas del Instituto Nacional de Migración indica que en 2010 deportaron 28,706 guatemaltecos; 23,788 hondureños; 10,502 salvadoreños. Mientras que en 2018 la cifra de devoluciones por las autoridades mexicanas registró un poco más de 100,000 (INM, 2018). Además, se ha intensificado la llegada de centroamericanos a las ciudades fronterizas, recurriendo a nuevas estrategias de viaje como las caravanas, tal es el caso de la que llegó a Tijuana en noviembre de 2018 integrada por más de 6,000 personas, provocando tensión social ante el

1 Este trabajo surge a partir de la participación de los autores en el trabajo colectivo La caravana centroamericana de migrantes en Piedras Negras, Coahuila 2019. Diagnóstico y Propuestas de acción, de El Colegio de la Frontera Norte.

2 Doctorado en Ciencias Sociales, Investigador Asociado B en El Colegio de la Frontera Norte en Piedras Negras, Coahuila, email:jesusfrausto@colef.mx. 3 Maestro en Planeación Agropecuaria, Asociado B en El Colegio de la Frontera Norte en Piedras Negras, Coahuila, email:parra03@hotmail.com. 
rechazo de un sector de la sociedad tijuanense (El Colef, 2018, pág. 1) y recientemente la ocurrida en febrero de 2019 en Piedras Negras, donde arribaron en caravana alrededor de 1,800 migrantes.

Se menciona que la primera caravana es la emprendida en 2011 por madres centroamericanas en busca de sus hijos (mujeres y hombres) desaparecidos en México, en ese tránsito hacia Estados Unidos. Si bien es cierto, el objetivo primordial de esa caravana se centraba en esa búsqueda y no en llegar a Estados Unidos, el movimiento se da en ese contexto de la migración de sus familiares. Además, un ingrediente peculiar de las últimas caravanas -las de 2018 y 2019- es la migración para solicitar asilo político principalmente en ese país. El acompañamiento de mujeres e incluso niños y niñas -acompañados o no- es otra de las características.

Este trabajo tiene por objetivo realizar un análisis sobre algunas características asociadas a la caravana migrante centroamericana que llegó a Piedras Negras en febrero de 2019.

\section{Metodología}

Para este trabajo se utilizó el cuestionario llamado "Condiciones de movilidad y estancia de la población de la caravana migrante" que se aplicó a la caravana migrante que llegó a Tijuana, B.C. en los últimos meses de 2018. El cual fue modificado para las condiciones de la caravana de centroamericanos que llegó a Piedras Negras el día 4 de febrero de 2019.

Antes de su aplicación se realizó una prueba piloto el día 9 de febrero con la participación de 6 encuestadores aplicando 5 cuestionarios cada uno. Después de la prueba piloto los días 11 y 12 de febrero se realizó la aplicación de los cuestionarios con la participación de 10 encuestadores ( 4 mujeres y 6 hombres). En total se aplicaron 535 cuestionarios en los dos días y se agregaron 5 de la prueba piloto dando un total de 540 cuestionarios; en los días siguientes fueron validados y capturados. Para el análisis de la base de datos se utilizó el programa SPSS versión 19 y se determinaron las frecuencias de las variables escogidas y para la elaboración de los cuadros se utilizó el programa Excel.

Asimismo, se realizaron 6 entrevistas dirigidas a población local se entrevistó a: un estudiante de preparatoria; un profesor universitario; un trabajador de la industria maquiladora; un profesionista dedicado al comercio, un funcionario público y un líder del comercio local. Por otro lado, se revisó información hemerográfica de la prensa local, regional e internacional y de radiodifusoras locales, así como artículos de revistas científicas.

\section{Discusión de resultados}

\subsection{Marco de referencia}

Como se señaló anteriormente México es un país de tránsito de migrantes provenientes en su mayoría de Honduras, El Salvador y Guatemala, así como de otros países centroamericanos, con rumbo a las ciudades fronterizas mexicanas donde esperan el momento adecuado para solicitar asilo o cruzar de indocumentados a la Unión Americana. En los últimos años se han intensificado las condiciones de pobreza, las desigualdades socioeconómicas, la falta de empleo, y la violencia en esos países centroamericanos convirtiéndolos en importantes expulsores de personas cuyo destino principal es Estados Unidos.

Una migración que tradicionalmente ha sido masculina, pero que en los últimos años se ha incrementado la femenina, y recientemente niñas y niños acompañados o no acompañados. El Cuadro $\mathrm{N}^{\circ} 1$ da cuenta de la importancia de las mujeres migrantes de esos países.

Por otro lado, Guatemala, Honduras y El Salvador conforman el denominado Triángulo Centroamericano del Norte (TCN), el cual es considerado como una de las regiones más peligrosas del mundo. Al respecto la Universidad Nacional Autónoma de Honduras (UNAH) y el Instituto Universitario en Democracia, Paz y Seguridad (IU-

Cuadro $\mathbb{N}^{0} 1$ Extranjeros devueltos a los países del Triángulo Norte de Centroamérica ${ }^{4}$

\begin{tabular}{|c|c|c|c|c|c|}
\hline País & Hombres & $\%$ & Mujeres & $\%$ & Total \\
\hline América Central & 82628 & 75 & 26879 & 25 & 109507 \\
\hline El Salvador & 8502 & 71 & 3501 & 29 & 12003 \\
\hline Guatemala & 32817 & 74 & 11437 & 26 & 44254 \\
\hline Honduras & 39953 & 77 & 11609 & 23 & 51562 \\
\hline Otros & 1356 & 80 & 332 & 20 & 1688 \\
\hline
\end{tabular}

Fuente: Elaborado con datos de (INM, 2018). 
DPAS) a través del Observatorio Nacional de la Violencia, publican que, en 2017 del total de muertes por causas externas en Honduras, el 55 por ciento fueron homicidios (UNAH-IUDPAS, 2018, pág. 1). Según el Global Report on Internal Displacement 2017 (GRID 2017), El Salvador en los últimos años ha sido uno de los países más violentos, en 2016 alrededor de 220,000 personas tuvieron que abandonar el lugar donde vivían a causa de la violencia (Internal Displacement Monitoring Center (IDMC), 2017, pág. 22). Por otro lado, según Hernández (2017, pág. 39), Guatemala está inmerso en elevados niveles de homicidio y violencia, que aunados a la desigualdad social entre otros factores provocan el desplazamiento de los guatemaltecos.

La violencia expuesta en los países del TNC juega un papel cada vez mayor como factor de expulsión de la población. En este sentido Varela (2016) afirma que la violencia, sea de género o de Estado, es una de las motivaciones para la fuga de esos países (pág. 178). Esto se puede observar en el aumento de las solicitudes de asilo de personas de esos países en busca de protección sobre todo en Estados Unidos; mientras que los gobiernos minimizan su efecto (Amnistía Internacional, 2016; UNHCR/ACNUR, 2017; Amnistía Internacional, 2018). Para darnos una idea en 2016 más de 60,000 personas de estos países solicitaron asilo en Estados Unidos (UNHCR/ACNUR, 2017). Por otro lado, se han incrementado significativamente las aprehensiones de centroamericanos hecho por la patrulla fronteriza en la frontera suroeste de Estados Unidos, como se observa en el Cuadro $\mathrm{N}^{\circ} 2$.

Sin embargo, los migrantes no solo en sus países de origen son víctimas de violencia, sino también, su tránsito por México se realiza en condiciones de alta vulnerabilidad pues es una ruta considerada de las más peligrosas del mundo y donde son víctimas de asaltos, extorsiones, secuestros y homicidios (Amnistía Internacional, 2010). En este mismo sentido, López (2013, pág. 79) realizó una encuesta en 2006-2007 a migrantes hondureños y el 72.9 por ciento contestó que en su tránsito por México fueron objeto de golpes, robos y amenazas.

En ese contexto, recientemente se ha experimentado una nueva modalidad migratoria realizada en caravanas que representa cierta seguridad para las y los migrantes y que visibiliza el trabajo de los albergues, la defensa de los migrantes y activan la respuesta solidaria de la gente (Martínez, 2018, pág. 233). De hecho, las caravanas están conformadas por víctimas de la violencia, la pobreza y la exclusión social (SEGOB/CONAPRED, 2018, pág. 3). Ante este fenómeno, las organizaciones de la sociedad civil que trabajan a favor de la causa migratoria o tienen como tema esa actividad, inciden en dos formas: por una parte, las organizaciones religiosas o laicas han creado espacios de atención migratoria; por la otra, aquellas abocadas en la modificación del marco legal el cual es la base de las limitaciones o posibilidades de la población migrante (Calderón, 2016, págs. 9 y 11). ${ }^{8}$ Como se observa, la migración en caravana visibiliza a las y los migrantes centroamericanos. Así, su tránsito por México permite que la sociedad mexicana se forme una opinión al respecto.

En ese sentido, otro aspecto a resaltar es la visión que tienen algunos mexicanos sobre las y los migrantes de la caravana. Reproducen las opiniones que se tienen sobre la migración mexicana en otros países, sobre todo en Estados Unidos: opiniones en un contexto de xenofobia y discriminación: juicios como "son delincuentes" "indeseables" o "nos quitarán los empleos", son algunos (SEGOB/CONAPRED, 2018). No obstante, como se deja entrever en el

Cuadro $\mathbb{N}^{\circ} 2$ Aprehensiones en la frontera suroeste de Estados Unidos por país

\begin{tabular}{|c|c|c|c|c|c|c|}
\hline \multirow{2}{*}{ País } & \multicolumn{2}{|c|}{ UAC } & \multicolumn{2}{c|}{ FMUA } & \multicolumn{2}{c|}{ SA } \\
\cline { 2 - 7 } & $2018^{5}$ & 2019 a marzo $^{6}$ & 2018 & 2019 a marzo & 2018 & 2019 a marzo \\
\hline El Salvador & 4,949 & 4,479 & 13,669 & 17,396 & 12,751 & 8,987 \\
\hline Guatemala & 22,327 & 16,392 & 50,401 & 90,447 & 42,994 & 25,799 \\
\hline Honduras & 10,913 & 9,138 & 39,439 & 72,728 & 26,161 & 20,583 \\
\hline
\end{tabular}

Fuente: Oficina de Aduanas y Protección Fronteriza de los Estados Unidos (CBP, 2019).

UAC: Niños extranjeros no acompañados, FMUA: Aprehensiones de Unidades Familiares SA: Adultos solteros ${ }^{7}$

5 Se refiere al año fiscal 2018.

6 Se refiere al año fiscal 2019 al mes de marzo.

7 Traducción de los autores.

8 En el segundo estarían organismos especializados que tienen que ver con aspectos legales-jurídicos de la migración con los derechos humanos. Ver la autora citada, pp. 9-13. 
documento, esas opiniones no corresponden con un contexto real del fenómeno migratorio en esas condiciones. En una encuesta nacional de 500 entrevistas hecha por teléfono, el 52 por ciento está de acuerdo con el libre paso de la caravana migrante y el 32 por ciento refiere que no se les debe dejar pasar (De las Heras, 2018). En ese sentido, para el 53 por ciento de la población mexicana opina que se le debe de dar refugio hasta que puedan regresar a su país y para un 33 por ciento se les debe dar papeles para que puedan trabajar en México (SEGOB/CONAPRED, 2018) ${ }^{9}$. No obstante, 4 de cada 10 mexicanos, hay una percepción de que los derechos de los extranjeros no se respetan en el país (González, 2014, pág. 6). En ese contexto, existen percepciones a favor de la migración centroamericana pero también hay expresiones de rechazo.

En síntesis, entre otras cosas, migrar en caravana permite: a) visibilizar a las y los migrantes; b) dar seguridad durante el viaje; c) obtener apoyo y/o protección de sus derechos humanos tanto de personas como de instituciones; d) demandar atención de las autoridades migratorias.

\subsection{Contexto general de Piedras Negras}

Piedras Negras es una ciudad fronteriza del Estado de Coahuila y tiene una población de 163,595 habitantes (INEGI, 2017). Colinda con Eagle Pass, Texas, localidad de 28,945 habitantes, datos para 2017 (United States Census Bureau (2019). Ambas ciudades fronterizas están delimitadas por el río Bravo, sobre el cual se construyeron dos puentes internacionales ${ }^{10}$ para realizar el intercambio comercial y para el cruce legal de personas hacia ambos países. Además, se construyó un puente de ferrocarril, utilizado solamente para el intercambio comercial. Como ejemplo de ese dinamismo en el comercio internacional, se tiene que las operaciones aduaneras: en 2016 por carretera fueron 96,242 exportaciones y 124,372 importaciones; mientras que por ferrocarril fueron 158,782 y 144,493 , respectivamente (Asociación de Agentes Aduanales de Piedras Negras, 2019).

Esos lugares de cruce son también vías utilizadas por la migración indocumentada para cruzar de México hacia Estados Unidos por esta frontera, a través de sortear y/o burlar a las autoridades migratorias estadounidenses. Sin embargo, la gran mayoría cruza a través de las aguas del río Bravo. Por ejemplo, 56 migrantes hondureños (entre ellos mujeres y niños de entre 4 y 16 años) que cruzaron el río a la altura del Puente Dos, fueron detenidos por la Patrulla Fronteriza (La Rancherita del Aire, 25 de marzo de 2019). La misma fuente señala que tan solo en un fin de semana se detuvieron más de 500 indocumentados y que en febrero un grupo de 90 personas se entregaron a la Patrulla Fronteriza. Esta forma subrepticia de cruce migratorio se convierte también en factor de riesgo: accidentes, muertes; extorsiones y/o secuestros por el crimen organizado o por la delincuencia. Al respecto una nota hace referencia al accidente de un hondureño-que perdió el pie izquierdo y varios dedos de su mano derecha- que viajaba en el tren con rumbo a Piedras Negras para internarse a Estados Unidos y una joven pareja junto con su bebé de aproximadamente dos años fue rescatada de morir en las aguas del río Bravo (Milenio Digital y Christian Sánchez, 2019).

Un problema que parece agravarse no sólo en esta región sino en general en la frontera, esto ha ocasionado que en los últimos meses se hayan incrementado las aprehensiones en el suroeste de EU, como lo indica el Cuadro $\mathrm{N}^{\circ} 3$.

Además, en Piedras Negras, como en todas las ciudades fronterizas mexicanas se cuenta con instancias de apoyo al migrante. En esta ciudad se cuenta con tres instancias

Cuadro $N^{\circ} 3$. Aprehensiones de la patrulla fronteriza en la frontera suroeste de Estados Unidos. Año Fiscal 2019.

\begin{tabular}{|c|c|c|c|c|c|c|c|c|}
\hline $\begin{array}{c}\text { Patrulla Fronteriza } \\
\text { de los Estados } \\
\text { Unidos }\end{array}$ & Población & Oct & Nov & Dic & Ene & Feb & Mar & Total \\
\hline \multirow{3}{*}{ Frontera Suroeste } & $\begin{array}{l}\text { Niños extranjeros no } \\
\text { acompañados }\end{array}$ & 4,968 & 5,259 & 4,755 & 5,113 & 6,828 & 8,975 & 35,898 \\
\hline & Unidades familiares* & 23,116 & 25,164 & 27,507 & 24,189 & 36,531 & 53,077 & 189,584 \\
\hline & Adultos solteros & 22,922 & 21,432 & 18,489 & 18,682 & 23,525 & 30,555 & 135,605 \\
\hline \multicolumn{2}{|c|}{$\begin{array}{l}\text { Total de aprehensiones en la frontera sur- } \\
\text { oeste }\end{array}$} & 51,006 & 51,855 & 50,751 & 47,984 & 66,884 & 92,607 & 361,087 \\
\hline
\end{tabular}

Fuente: Tomado de Patrulla Fronteriza de los Estados Unidos (USBP 2019).

*Unidad Familiar: representa el número de personas (sea un niño menor de 18 años, padre o tutor legal) aprehendidas con un miembro de la familia por la patrulla fronteriza ${ }^{11}$

9 Datos de la Encuesta Nacional Sobre Discriminación 2017.

10 El Puente Uno (Piedras Negras-Eagle Pass) por el que cruzan personas y automóviles; El Puente Dos (Coahuila 2000-Camino Real) por el que cruzan personas y el comercio internacional y; El Puente Negro (Charles Frisby) del Ferrocarril para la importación y exportación de mercancías por esa vía. 11 Traducción de los autores. 
de atención de migrantes indocumentados no mexicanos: Casa del Migrante Ejército de Salvación y Casa del Migrante Frontera Digna (apoyan a los migrantes con alimentos, ropa y estancia, principalmente, con las donaciones que hace la población); así como la delegación de migración. Estas instancias fueron creadas para atender a pequeños grupos de migrantes y no tienen capacidad para atender a flujos numerosos de migración extranjera como la ocurrida con la caravana de febrero de 2019. Este fue uno de los principales factores que tuvieron que sortear los tres niveles de gobierno (federal, estatal y municipal) para atender a las casi 1,800 personas que llegaron en caravana provenientes de Centroamérica a Piedras Negras en febrero de 2019. Así como la capacidad de atención de las autoridades migratorias estadounidenses en el trámite de peticiones de asilo político (una de las principales demandas de los migrantes centroamericanos de la caravana), que es de alrededor de 8 a 12 trámites que puede realizar la oficina de control y protección de la frontera (CBP).

\subsection{Características de los migrantes que conforman la caravana migrante}

Las personas migrantes que llegaron en la caravana a Piedras Negras señalaron que el principal motivo por el que salieron de sus países fue la falta de empleo o por motivos económicos. Sin embargo, un porcentaje importante (32 por ciento) señalan a la inseguridad y la violencia como condicionantes de esa migración (Cuadro №4).

Cuadro $N^{\circ} 4$. Motivos por los que se unieron a la caravana.

\begin{tabular}{|c|c|c|}
\hline Motivo Principal & Frecuencia & $\%$ \\
\hline $\begin{array}{c}\text { Falta de empleo o medios } \\
\text { económicos }\end{array}$ & 348 & 65.0 \\
\hline Inseguridad y violencia & 172 & 32.2 \\
\hline Presiones políticas & 7 & 1.3 \\
\hline Otros & 8 & 1.5 \\
\hline Total & $\mathbf{5 3 4}$ & $\mathbf{1 0 0 . 0}$ \\
\hline
\end{tabular}

Fuente: Elaboración propia con resultados del cuestionario aplicado a migrantes en Piedras Negras, Coahuila, en febrero de 2019.

En ese contexto en donde la inseguridad y la violencia es uno de los factores de emigración, tal vez se entiende mejor cuando se observa las razones para ir a Estados Unidos o cruzar mediante otra forma a ese país. En ese sentido, un 60 por ciento de esa población piensa llegar a ese país: 39 por ciento solicitando asilo y 21 por ciento cruzando de cualquier manera (Cuadro $\mathrm{N}^{\circ} 5$ ).
Cuadro $N^{\circ} 5$ Ahora que está en Piedras Negras ¿qué piensa hacer?

\begin{tabular}{|c|c|c|}
\hline Motivo & Frecuencia & $\%$ \\
\hline Solicitar Asilo en EU & 197 & 39.0 \\
\hline Cruzar a EU & 104 & 20.6 \\
\hline Quedarse en Piedras Negras & 109 & 21.6 \\
\hline Ir a otro lugar México & 77 & 15.2 \\
\hline Regresar a su lugar de origen & 5 & 1.0 \\
\hline Otro & 13 & 2.6 \\
\hline Total & $\mathbf{5 0 5}$ & $\mathbf{1 0 0 . 0}$ \\
\hline
\end{tabular}

Fuente: Elaboración propia con resultados del cuestionario aplicado a migrantes en Piedras Negras, Coahuila, en febrero de 2019.

Como se señaló, una de las ventajas de migrar en caravana es la seguridad de las y los migrantes. Sin embargo, eso no garantiza que durante su trayecto -sobre todo en el territorio mexicano- para llegar a Estados Unidos no corran riesgos. Tal es el caso de los peligros que corren según su forma de viaje que se traducen principalmente en accidentes, también enfrentan -como se mencionó en el apartado anterior- abusos, violaciones e incluso la muerte, por parte de delincuentes, del crimen organizado y por elementos de las autoridades mexicanas.

En el Cuadro $\mathrm{N}^{\circ} 6$, se puede observar las respuestas de las y los migrantes de la caravana migrante a Piedras Negras que contestaron haber sufrido maltrato por las autoridades mexicanas. Como se observa, las autoridades del orden federal son las instancias que más mencionaron como origen de la agresión. La policía federal (31\%) y el INM (28\%) fueron las instituciones más señaladas.

Cuadro N6 Agresión o maltrato a los migrantes por tipo
\begin{tabular}{|c|c|c|}
\hline \multicolumn{3}{|c|}{ de autoridad } \\
\hline Autoridad & Frecuencia & $\%$ \\
\hline INM & 11 & 28.2 \\
\hline Grupo Beta & 2 & 5.1 \\
\hline Policía Federal & 12 & 30.8 \\
\hline Policía Estatal & 2 & 5.1 \\
\hline Policía Municipal & 3 & 7.7 \\
\hline Ejército & 1 & 2.6 \\
\hline Otro & 8 & 20.5 \\
\hline Total & 39 & 100.0 \\
\hline
\end{tabular}

Fuente: Elaboración propia con resultados del cuestionario aplicado a migrantes en Piedras Negras, Coahuila, en febrero de 2019.

Por otro lado, la dureza de la política migratoria de Estados Unidos y la lentitud de atención de las peticiones de asilo 
de los migrantes por el gobierno norteamericano ha orillado que muchos de ellos (incluso familias completas) recurran a cruzar en forma ilegal hacia ese país. Lo cual representa riesgos en el cruce e incluso la muerte en el río Bravo. En este sentido, se les preguntó si en ese momento les gustaría regresar a su país de origen y el 95 por ciento señaló que no. A estas personas se les preguntó porque no querían regresar respondiendo un 31 por ciento por factores de violencia en sus lugares de origen y con ello miedo a regresar, así como la existencia de mejores oportunidades fuera de sus países y la falta de trabajo (38 por ciento ambas) son razones importantes para no querer regresar a Centroamérica (Cuadro $\mathrm{N}^{\circ} 7$ ).

Cuadro $\mathbb{N}^{0} 7$ ¿Por qué no le gustaría regresar a su lugar de origen?

\begin{tabular}{|c|c|c|}
\hline Motivo & Frecuencia & Porcentaje \\
\hline $\begin{array}{c}\text { Aquí hay más } \\
\text { oportunidades }\end{array}$ & 134 & 27.7 \\
\hline $\begin{array}{c}\text { Tengo familiares (México } \\
\text { o EU) y quiero estar cerca }\end{array}$ & 18 & 3.7 \\
\hline $\begin{array}{c}\text { Quiero llegar a EU } \\
\text { No hay trabajo de dónde } \\
\text { vengo }\end{array}$ & 83 & 17.2 \\
\hline $\begin{array}{c}\text { Violencia en lugar de } \\
\text { origen }\end{array}$ & 111 & 10.6 \\
\hline Tengo miedo regresar & 40 & 8.3 \\
\hline Otro & 46 & 9.5 \\
\hline Total & 483 & 100.0 \\
\hline
\end{tabular}

Fuente: Elaboración propia con resultados del cuestionario aplicado a migrantes en Piedras Negras, Coahuila, en febrero de 2019.

Si bien es cierto que las y los migrantes salieron en caravana de sus países con el objetivo de llegar a Estados Unidos, es probable que el endurecimiento de las políticas migratorias de asilo de Estados Unidos y las condiciones de violencia e inseguridad que ellas y ellos enfrentan en sus países (sobre todo de los países que mayormente conforman esta caravana: Honduras, Guatemala y El Salvador), y el conocimiento sobre los requisitos para conseguir asilo en aquél país, haya hecho reflexionar a muchas y muchos de los migrantes, puesto que el 37 por ciento señaló quedarse a vivir en México (22 por ciento quedarse en Piedras Negras y 15 por ciento ir a otro lugar de México). Sin embargo, ante las condiciones señaladas para cruzar a Es- tados Unidos, tal vez ello sea una decisión provisional y en algún momento dado las y los migrantes intenten cruzar legal o ilegalmente al vecino país. Eso es motivo de otros estudios, este trabajo no abunda al respecto.

\subsection{Opiniones de solidaridad y rechazo de la caravana ${ }^{12}$}

La llegada de las caravanas de migrantes centroamericanos a la frontera norte ha generado expresiones de solidaridad y de rechazo por parte de la población. En ese sentido, este apartado muestra las expresiones de la población de Piedras Negras-Eagle Pass sobre la caravana migrante.

Con respecto a las expresiones de solidaridad hacia la caravana de migrantes centroamericanos, estas se manifestaron por medio de las organizaciones de la sociedad civil a través de la ayuda con diversos enseres como: ropa, medicamentos, juguetes, comida, entre otros. En ese contexto de solidaridad, un líder religioso mencionaba que "todos estamos formando un frente en esta contingencia" (Días Balderas en La Rancherita del Aire, 8 de febrero de 2019a). Esa visión de ayuda para algunos de los entrevistados es parte de las características culturales de los mexicanos, ya que es una distinción de México solidarizarse con los hermanos de otros países (Profesionista, comunicación personal, febrero de 2019).

Como ejemplo de la participación de las organizaciones de la sociedad civil se tiene que: la Cruz Roja hizo entrega de artículos de higiene personal; las diferentes iglesias de la región donaron ropa para los migrantes a través del DIF de Piedras Negras.

Diversos grupos de profesionistas también manifestaron su apoyo. Así, un grupo de psicólogos que ofrecieron consultas a los migrantes en situación de depresión y estrés (La Rancherita del Aire, 8 de febrero de 2019b). Otro de feligreses católicos apoyó con actividades musicales y lúdicas para los integrantes de la caravana. En esa perspectiva de apoyo, algunos residentes locales opinan que hay que hacerlo porque los migrantes buscan un mejor futuro para sus familias y por ello estaría dispuesto ayudar con comida o incluso dinero, siempre y cuando ellos no cometan vandalismo (Operario de fábrica, comunicación personal, febrero de 2019).

En Piedras Negras no se dieron manifestaciones de rechazo de la población a través de manifestaciones en las calles como si se dio en la caravana de Tijuana. Algunos entrevistados opinaron que eso no sucedió los migrantes estu-

12 Esta sección se adecuó para este artículo de la versión que forma parte del proyecto La Caravana Migrante de Piedras Negras Coahuila 2019. Diagnóstico y Propuestas de acción, de El Colegio de la Frontera Norte, en la cual participaron los autores y Blanca Vázquez. 
vieron contenidos en un albergue y no salieron a las calles. Estuvieron en un espacio donde tuvieron todo: servicio de internet, comida tres veces al día, cobijas, colchonetas para dormir, agua corriente fría y caliente, regaderas; así como, servicios médicos y medicamentos, entre otros. De hecho, el traslado de los migrantes en camiones por el Estado de Coahuila y su "confinamiento" en el albergue, para uno de los entrevistados fue para administrar y contener el flujo de migrantes y evitar que se dispersaran por las calles y generaran problemas de inseguridad a la población (Pliego Corona, en La Rancherita del Aire, 6 de febrero de 2019a).

Esas opiniones también se encuentran en otros líderes locales. Es el caso del Presidente Municipal para quién las decisiones adoptadas de apoyo a los migrantes no son privilegios sino medidas para resguardar la tranquilidad y la paz de la población (La Rancherita, 6 de febrero de 2019b). En ese mismo tema, ante la posibilidad del cierre del Puente Internacional Dos, la presidenta de INDEX celebraba las estrategias de contención de la migración ya que ello permitía que el puente siguiera abierto y se pudiera seguir cruzando las mercancías (Blanca Tavares en La Rancherita del Aire, 10 febrero de 2019).

Por otro lado, como se comentó, también se presentan las expresiones de rechazo por la población. En esas manifestaciones están las de rechazo o de recelo hacia las autoridades locales por los "privilegios" dados a los migrantes centroamericanos. Por lo general estas opiniones se hicieron en los medios de comunicación o en las redes sociales, pero también se captaron en las entrevistas realizadas. Esas herramientas fueron muy importantes en la visibilización de la caravana. En ese sentido, para un entrevistado la gente no se manifestó en las calles, pero sí en las redes sociales y lo hizo de manera negativa (Profesor universitario, comunicación personal, febrero de 2019). El hecho de que se apoye a la caravana, no quiere decir que se esté de acuerdo con los políticos que la apoyaron, esa opinión la tiene otra persona entrevistada, quien además menciona que sus amigos y familiares comparten dicha opinión, la de ayudar por solidaridad. (Profesionista, comunicación personal, febrero de 2019). Para otro entrevistado, esa molestia de la ciudadanía está relacionada con los rezagos que hay en Piedras Negras; en las calles, en el trabajo, entre otros (El Colef, 2019).

Esto es, el rechazo no necesariamente es hacia las personas de la caravana, sino hacia las autoridades que "privilegiaron" su atención en aras de sacrificar las necesidades de la población local y usar los recursos públicos en be- neficio de población extranjera. En ese sentido, para la población de Piedras Negras no es aceptable desatender a la sociedad local para atender las necesidades de centroamericanos. Al respecto, un empresario local opinaba que la gente está celosa de las facilidades otorgadas a los migrantes, las que incluso no se tienen en México (El Colef, 2019).

Los reclamos en particular eran por la falta de medicamentos para la población de Piedras Negras. En específico se mencionaba su carencia en el Hospital General. Mientras que los migrantes si los tenían en el albergue. Contaban con una farmacia y atención médica e incluso servicios dentales (la Rancherita del Aire, 6 de febrero de 2019c). Sin embargo, los reclamos parecen no ser hacia las autoridades en sí, sino por lo que éstas han dejado de hacer: el abandono de la población local por la política social de atención médica. Para uno de los entrevistados, la gente sacó las deficiencias que tienen y personas que huyen de su situación económica -los centroamericanos-, no dejan de causar molestias (Profesor universitario, comunicación personal, febrero de 2019).

Algunos jóvenes conciben al suceso como algo catastrófico para la ciudad y que además se gastan recursos en beneficio de los migrantes, al grado de considerar que se ayudó a gente de otros países y no a los mismos paisanos (Estudiante, comunicación personal, febrero de 2019). Para este joven fue buena idea tener a los migrantes en un albergue para que no "vagaran" por la ciudad.

En esas visiones negativas, un profesor opina que se usaron impuestos de los mexicanos para atender a los centroamericanos, los cuales se necesitan ya que en el país también hay necesidades. De igual manera, el referente de este profesor es la falta de medicamentos en este caso para la población con seguridad social; incluso, que a veces hay población de edad mayor que le extienden el período de entrega de medicamentos, lo que califica como una situación injusta (Profesor universitario, comunicación personal, febrero de 2019). Considera que esa misma opinión negativa la tienen familiares y amigos cercanos.

Vecinos de Eagle Pass, Texas también expresaron preocupaciones por la migración de centroamericanos a esta región. Una comunidad conformada en un 95 por ciento de población de origen hispano o latino. En particular mostraban temor de cruzar a México -a Piedras Negras- ante la llegada de los migrantes centroamericanos a esta ciudad; mayormente luego de los disturbios que armaron los mi- 
grantes al interior del albergue, evento que se documentó en la prensa local (Barboza, 15 de febrero de 2019).

Esas expresiones recogidas por los medios de comunicación procedían de las redes sociales. Ambas herramientas de información fueron básicas para visibilizar la caravana migratoria en Piedras Negras se hicieron a través de las redes sociales. Prestadores de servicios como los dentistas referían que sus clientes de Eagle Pass cancelaban sus citas por el miedo a cruzar a México por la llegada de los migrantes centroamericanos (La Rancherita del aire, 13 de febrero de 2019).

\section{Conclusiones}

Los motivos principales por los que los migrantes se unieron a la caravana que llegó a Piedras Negras fueron la falta de empleo y cuestiones económicas, así como la inseguridad y la violencia en su país de origen. Al viajar en caravana los migrantes centroamericanos tuvieron mayor seguridad en su tránsito por México, solo un pequeño grupo tuvo ciertos problemas de inseguridad, sobre todo con autoridades mexicanas como la policía federal y el Instituto Nacional de Migración. El 60 por ciento de los migrantes encuestados manifestaron su deseo de llegar a los Estados Unidos (E.U); mientras que el 37 por ciento respondió que se quedaría en México en busca de mejorar su situación económica y la de su familia. Enfatizando: la población migrante que llegó a Piedras Negras piensa solicitar asilo en E.U. (39\%) o cruzar a ese país (20\%). Si se considera además los que dijeron se quedarían en esta ciudad (22\%), se puede asumir que la mayoría de los migrantes que componían la caravana piensa llegar, de una manera u otra, a E.U. Por otra parte, la gran mayoría de las personas que llegaron en la caravana no piensa regresar a su país de origen, debido a la falta de oportunidades, la inseguridad y la violencia que existe en su país. Por otro lado, las restricciones relacionadas con la capacidad de atención a las y los migrantes para tramitar el asilo político en Estados Unidos y las medidas de vigilancia implementadas por el gobierno de ese país, han provocado que los migrantes busquen alternativas de cruce migratorio y una de ellas ha sido hacerlo de manera ilegal por el río Bravo, aumentando los riesgos que las y los migrantes corren para cruzar a ese país. Peligros incluso de muerte por ahogamiento en las aguas de dicho río.

En lo referente a la población de Piedras Negras, ésta manifiesta opiniones ambivalentes sobre la caravana migrante. Por una parte, señala expresiones de solidaridad y apoyo a la misma; por la otra, tiene opiniones de rechazo. Esto último se asocia con las carencias que adolece la población local y que se las proporcionaron a las y los migrantes: como servicios médicos y medicamentos. En la práctica, la solidaridad y apoyo fue de la sociedad organizada y de las instancias de gobierno de los tres niveles (federal, estatal y local). En ese sentido, las opiniones de las personas entrevistadas recogen las dos posturas sobre la percepción que la población en México tiene sobre la migración centroamericana: a) la de solidaridad con las y los migrantes y su manifestación de ayuda sobre todo por las organizaciones de la sociedad civil; b) manifestaciones de rechazo hacia las y los migrantes. Sin embargo es necesario hacer más investigación al respecto, este trabajo es un primer acercamiento al tema de estudio referido en esta ciudad fronteriza de México con Estados Unidos.

\section{Referencias bibliográficas}

- Amnistía Internacional (2010). Víctimas invisibles. Migrantes en movimiento en México. Madrid, España: EDAI. Recuperado de https://www.acnur.org/fileadmin/Documentos/archivo/7756.pdf?view=1.

- Amnistía Internacional (2016). ¿Hogar dulce hogar? El papel de Honduras, Guatemala y El Salvador en la creciente crisis de refugiados. London, Reino Unido: Amnesty International. Recuperado de https://www.amnesty.org/ download/Documents/AMR0148652016SPANISH.PDF.

- Amnistía Internacional (2018). Ignoradas y sin protección. London, Reino Unido: Amnesty International. Recuperado de https://amnistia.org.mx/contenido/wp-content/ uploads/2018/01/Briefing-Ignoradas-y-Sin-Protecci\%C3\%B3n-SPANISH-05.pdf

- Asociación de Agentes Aduanales de Piedras Negras / CAAAREM/AAMX (2017). 50 Aniversario 1967-2017 de la Asociación de Agentes Aduanales de Piedras Negras.

- Barboza Estrada, M. (15 de febrero de 2019). Preocupa a vecinos deEPla situación demigrantes.PeriódicoZócalo. Recuperado de http://www.zocalo.com.mx/new_site/articulo/ preocupa-a-vecinos-de-ep-la-situacion-de-migrantes.

- Calderón L. (2016). La sociedad civil organizada ante la migración en tránsito en México. CANMID Policy Brief Series \# 13. Guadalajara, México: CIESAS. Recuperado de http:// www.canamid.org/descargas/policies/canamid-pb013-es. pdf.

- De Las Heras/Nemotecnia (2018). Encuesta Caravana Mi- 
grante. Recuperado de http://www.demotecnia.com.mx/ caravana-migrante/.

- El Colegio de la Frontera Norte (EL COLEF). (2018). La caravana de migrantes centroamericanos en Tijuana 2018. Diagnóstico y propuestas de acción. Tijuana: El Colegio de la Frontera Norte.

- El Colegio de la Frontera Norte. (EL COLEF) (2019). La caravana centroamericana de migrantes en Piedras Negras, Coahuila 2019. Diagnóstico y propuestas de acción. Tijuana: El Colegio de la Frontera Norte.

- González Rosas, J. (Diciembre de 2014). Migrantes centroamericanos en México. Un estudio de opinión sobre el respeto de los derechos humanos. Letras Migratorias/

- Newsletter. Recuperado de http://omi.gob.mx/work/ models/OMI/Resource/1303/1/images/Newsletter_Javier_Gonzalez1.pdf.

- Hernández Bonilla, S. (2017). Detonantes del desplazamiento interno en Guatemala. Recuperado de https://rua. ua.es/dspace/bitstream/10045/70592/1/RMF_56_18.pdf.

- IDMC. (2017). Global Report on Internal Displacement 2017. Recuperado de http://www.internal-displacement. org/global-report/grid2017/pdfs/2017-GRID.pdf

- Instituto Nacional de Estadística Geografía e Informática (INEGI) (2017). Anuario estadístico y geográfico de Coahuila de Zaragoza 2017. Recuperado de http://www. datatur.sectur.gob.mx/ITxEF_Docs/COAH_ANUARIO_PDF. pdf.

- Instituto Nacional de Migración (INM) (2018). Boletín de Estadísticas Migratorias, Mujeres y Hombres. III. Las y los extranjeros devueltos y presentados, 2018. Cuadro 3.3. Recuperado de http://www.politicamigratoria.gob.mx/ es_mx/SEGOB/CuadrosB_MyH?Anual=2018\&Secc=3

- La Rancherita del Aire (6 de febrero de 2019c). Instalan dos consultorios médicos, dos dentales y una farmacia en albergue de migrantes. Recuperado de https://rancherita. com.mx/noticias/detalles/61846/instalan-dos-consultorios-medicos-dos-dentales-y-una-farmacia-en-albergue-de-migrantes.html\#.XGb7EORKgps.

- La Rancherita del Aire (8 de febrero de 2019a). Iglesias cristianas forman un frente común para donar ropa a migrantes. Recuperado de https://rancherita. com.mx/noticias/detalles/61952/iglesias-cristianas-forman-un-frente-comun-para-donar-ropa-a-migrantes. html\#.XHgwM4IKgps.

- La Rancherita del Aire (8 de febrero de 2019b). Atienden cuadros de depresión en albergue de migrantes 15 psicólogos voluntarios. Recuperado de https://rancherita.com. $\mathrm{mx} /$ noticias/detalles/61928/atienden-cuadros-de-depresion-en-albergue-de-migrantes--psicologos-voluntarios. html\#.XGb3mORKgps.

- La Rancherita del Aire (6 de febrero de 2019a).Traslado de migrantes en camiones fue para evitar que se dispersaran: Secretario de Seguridad. Recuperado de https://rancherita.com.mx/noticias/detalles/61862/traslado-de-migrantes-en-camiones-fue-para-evitar-que-se-dispersaran-secretario-de-seguridad.html\#.XGb58eRKgps.

- La Rancherita del Aire (6 de febrero de 2019b). Atención a migrantes no son privilegios, es evitar que se perturbe la tranquilidad de los nigropetenses: Alcalde. Recuperado de https://rancherita.com.mx/noticias/detalles/61859/ atencion-a-migrantes-no-son-privilegios-es-evitar-que-se-perturbe-la-tranquilidad-de-los-nigropetenses-alcalde.html\#.XGb6J-RKgps.

- La Rancherita del Aire (10 febrero de 2019). Agradece Index al alcalde por estrategia de contención de migrantes y que puentes siguen abiertos. Recuperado de https:// rancherita.com.mx/noticias/detalles/62007/agradece-index-al-alcalde-por-estrategia-de-contencion-de-migrantes-y-que-puentes-siguen-abiertos.html\#.XGbOVuRKgps.

- La Rancherita del Aire (25 de marzo de 2019). Arrestaron en Eagle Pass a 56 indocumentados, fueron más de 500 este fin de semana. Recuperado de https://rancherita.com. $\mathrm{mx} /$ noticias/detalles/64047/arrestaron-en-eagle-pass-a-indocumentados-fueron-mas-de--este-fin-de-semana. html\#.XJpDXsIKiUk.

- La Rancherita del Aire (13 de febrero de 2019). Clientes americanos ya no vienen a Piedras Negras, se quejan dentistas. Recuperado de https://rancherita.com.mx/noticias/ detalles/62142/clientes-americanos-ya-no-vienen-a-piedras-negras-se-quejan-dentistas.html\#.XHgsNYIKgps.

- López Recinos, V. (2013). Desarrollo migración y seguridad: El caso de la migración hondureña hacia Estados Unidos. Migración y Desarrollo, 11(21), 65-105.

- Márquez Covarrubias, H. (2015). No vale nada la vida: éxodo y criminalización de migrantes centroamericanos en México. Migración y Desarrollo, 13 (25), 151-173. Recuperado de http://www.redalyc.org/pdf/660/66046497006. pdf.

- Martínez Hernández, I. (2018). Reflexiones sobre la ca- 
ravana migrante. Análisis Plural. 231-248. Recuperado de https://rei.iteso.mx/bitstream/handle/11117/5616/S3\%20 Reflexiones\%20sobre\%20la\%20caravana\%20migranteAjustado.pdf?sequence $=2$.

- Milenio Digital y Christian Sánchez. (11 de Febrero de 2019). Familia hondureña casi muere al intentar cruzar a EU por segunda vez. Recuperado de https://www.milenio. com/estados/familia-hondurena-casi-muere-al-intentar-cruzar-a-eu-por-segunda-vez.

- SEGOB/Consejo Nacional para la Discriminación (CONAPRED) (2018) Mitos y realidades sobre la Caravana migrante y las personas refugiadas. Recuperado de https:// www.conapred.org.mx/userfiles/files/Mitos\%20y\%20realidades_caravana\%20\%281\%29.pdf.

- UNAH-IUDPAS. (2018). Mortalidad y otros. Boletín enero-diciembre 2017, núm. 48, p. 1-16. Tegucigalpa: Observatorio Nacional de la Violencia. Recuperado de file:///C:/ - Users/Home/Downloads/BoletinNacionalEneroDiciembre2017-web.pdf.

- UNHACR/ACNUR (Febrero de 2017). Situación del triángulo norte de Centroamérica. Recuperado de https:// www.acnur.org/fileadmin/Documentos/BDL/2017/11040. pdf.

- United States Census Bureau (2019). Recuperado de https://www.census.gov/quickfacts/eaglepasscitytexas.

- Us Custom Border Protection (USBP). (2019). Recuperado de https://www.cbp.gov/newsroom/stats/ sw-border-migration/usbp-sw-border-apprehensions.

- Us Custom Border Protection (CBP). (2019). Recuperado de https://www.cbp.gov/newsroom/stats/ sw-border-migration.

- Varela, A. (2016). Capítulo 12. Del silencio salimos: la Caravana de madres hondureñas en México. Un ejemplo de resistencias en clave femenina al régimen global de fronteras. Recuperado de http://investigacion.cephcis.unam. $\mathrm{mx} /$ generoyrsociales/wp-content/uploads/2016/04/Del_ silencio_salimos_la_Caravana_de_madr.pdf. 